\title{
Physical activity among newly immigrated Latino adults
}

\author{
Jie W. Weiss, ${ }^{1}$ Daniela Rubin, ${ }^{2}$ and Jessica N. Gomel ${ }^{3}$ \\ ${ }^{1}$ Department of Health Sciences \\ ${ }^{2}$ Department of Kinesiology \\ ${ }^{3}$ Department of Child and Adolescent Studies \\ California State University, Fullerton
}

\begin{abstract}
Latinos are disproportionately represented among overweight, obese, and unfit adults, putting them at higher risk for compromised health. This study examined weight status and usage of an aerobics program established within a residential complex among a sample of low-income, recently immigrated Latino adults (94 women/53 men). Results demonstrated that most participants were overweight or obese (79\%) and physically inactive $(59.1 \%)$. Results also indicated that while walking was the most common type of physical activity for both men and women, there are significant gender differences in other types of physical activities, in that housework was a more prevalent type of activity for women than men and yard work is a more prevalent activity for men. Furthermore, more women reported going to the exercise class than men while men reported to be more engaged in sports. The finding of this study provided valuable insights on the risk perception of being overweight and its connection to health, as well as useful information about the barriers to the physical activity and preferences for specific physical activities for this population.
\end{abstract}

(C) 2009 Californian Journal of Health Promotion. All rights reserved.

Keywords: physical activity, health status, obesity, Latinos

\section{Introduction}

Overweight and obesity have increased at alarming rates and become highly pressing public health concerns in the United States. It is ranked, after smoking, as the second leading cause of preventable death in the United States (Mokdad, Marks, Stroup, \& Gerberding, 2004). Minority groups, most notably Hispanic and African American women, have the highest prevalence (Nelson, Gortmaker, Subramanian, Cheung, \& Wechsler, 2007; Sanchez-Johnson et al., 2004). Latino adults are disproportionately represented among overweight and obese individuals in the United States (Flegal, Carroll, Ogden, \& Johnson, 2006; Goel, McCarthy, Phillips, \& Wee, 2004). According to the National Health and Nutrition Examination Survey (NHANES), about $75.8 \%$ of Latino adults were overweight or obese (BMI $>25)$ in
2003-2004 (Hubert, Snider, \& Winkleby, 2004; Ogden et al., 2006). In Orange County, California, where there is a high density of Latino residents, nearly 7 out of 10 Latino adults are overweight or obese (California Department of Health Services, 2005; California Health Interview Survey, 2003). These disturbingly high rates of weight problems among the Latino population may lead to severe health consequences including type 2 diabetes, some cancers, and heart disease.

Although the contribution of genetic factors to the predisposition of obesity is well documented, there are other risk factors for obesity. Behavioral determinants such as physical inactivity have been established as a key contributing factor to the obesity epidemic (Bernstein, Costanza, \& Morabia, 2004; Heini \& Weinsier, 1997). Much research suggests that 
the decrease in energy expenditure associated with sedentary behavior is a key contributing factor to the obesity epidemic (Brownson et al., 2000; Schmitz, Jacobs, Leon, Schreiner, \& Sternfeld, 2000). A higher level of physical activity is negatively correlated with overweight and obesity (Erlichman, Kerbey, \& James. 2002; Fogelholm \& Kukkonen-Harjula, 2000), and frequent moderate to vigorous physical activity is associated with weight maintenance and an attenuation of weight gain over a period of 10 years (Carnethon, Gulati, \& Greenland, 2005; Littman, Kristal, \& White, 2005). The low participation rates in physical activity lead to further concern because sedentary behavior has been independently associated with increased risk for various diseases and health conditions (Carnethon et al., 2005; Gregg et al., 2005).

Previous studies suggested that Latinos present low levels of leisure-time physical activity as well as low levels of cardiovascular fitness (Crespo, Smit, Carter-Pokras, \& Andersen, 2001; Marquez \& McAuley, 2006). Latinos were reported to have rates of physical inactivity ranging from $27 \%$ to $56 \%$ depending on gender and age, with women being less active than men. Although Eyler et al. (2003) reported that body mass index and physical activity were inversely related among White women, there is a paucity of information on level of physical activity, weight status, and risk for obesity in the Latino population. These specific variables need to be better understood in this ethnic group in order to develop effective intervention programs.

The purpose of the current study was to examine the extent to which the sample utilized the physical activity program that was offered to them and to discuss other factors, such as barriers to physical activity that may influence the participation in the exercise program as well as overweight status, based upon BMI, and perceptions of overweight and its risk to overall health. Challenges in conducting research among this population were also discussed.

\section{Methods}

\section{Sample}

\section{Locating Potential Participants.}

This study was conducted in a publiclysubsidized residential community comprised of 356 units, located in Santa Ana, California. Residents were primarily Spanish-speaking, newly immigrated, low-income Latinos. People choose to live in the community for various reasons, including speaking a familiar language in the neighborhood, easy access to traditional foods and cultural events, and recruitment by friends and relatives. This kind of population is relatively understudied due to their low level of literacy and lack of knowledge regarding research. In addition, it is hard to reach them since many of the adults work long hours during the day and sometimes they also work during the weekend.

\section{Securing Cooperation from Intermediaries.}

The process of recruitment in such communities generates an array of seldom-discussed practical challenges. Previous experience with the recruiting effort has provided valuable insights that are relevant to any study in which intermediaries control access to participants (Weiss \& Weiss, 2002). There is an administrative chain of command to be negotiated. We asked the county health department to identify a key city official, who in turn suggested a particular residential complex because of her close relationships with local staff. The staffers maintain an on-site office that serves as a social and administrative Center for the complex. With introductions facilitated in this personal manner, we were able to speak directly with the on-site staff. We then enlisted two staff members who would be our representatives in carrying out the study. By utilizing these staff members, to whom we gave token payments for their assistance, as our agents, we were able to take advantage of the trust they had already established with residents. 


\section{Procedure}

The staff members distributed a survey package that included a questionnaire and consent form (in both English and Spanish) into the 347 mailboxes in the complex. Residents were asked to read and sign the consent forms if they agreed to participate, with a $\$ 10$ payment offered to those who completed the surveys. Those who participated had to have their height and weight measured (by the staff members) at the Center. The study was conducted in accord with APA policy, under ethical guidelines overseen by the California State University, Fullerton Institutional Review Board.

Of 356 households who were approached, 186 sent in the consent form. Of those, 147 provided completed surveys and our data analysis was based on this sample. All the participants reported coming from Mexico to the U.S. after 1994. Nearly two-thirds of the respondents were female $(64.2 \%$ female), and most were between the ages of 20 and $39(84.1 \%)$. Most respondents were married $(80.4 \%)$, were parents with children living at home (93.8\%), and reported a household income of less than $\$ 35,000 \quad(94.7 \%)$, which indicates low socioeconomic status.

\section{Measures}

Questionnaire items and the consent form were maintained at 5-th grade level (using Microsoft WORD's readability statistics) to accommodate the relatively low level of education in this population. Documents were then translated into Spanish by the second author and then independently back-translated into English by a bilingual graduate assistant to confirm that the materials were comparable. The Spanish version of the questionnaire was pilot-tested with small groups of residents in the targeted apartment complex to identify any potential wording ambiguities.

\section{Demographic information}

Demographic variables include self-reported age, gender, ethnicity, immigration status, education, employment status, income, and number of children in the household.
The Body Mass Index (BMI) was calculated using the standard weight/height formula. Based on the BMI calculations, the participants were divided into three groups: normal weight (i.e., BMI $=20-24.99 \mathrm{~kg} / \mathrm{m} 2$ ), overweight (i.e., BMI $=25-29.99 \mathrm{~kg} / \mathrm{m} 2$ ), and obese (i.e., BMI $\Rightarrow$ $30 \mathrm{~kg} / \mathrm{m} 2$ ) (Centers for Disease Control and Prevention, 1998). No one had a BMI under 20.

\section{On-site aerobics program}

Because it can be difficult for residents of the complex to get regular exercise, the Center staff had established a free, on-site aerobics class that met twice weekly. At the time of the survey, the class had been offered for nearly one year. The classes were taught by a volunteer who was also a resident, and were generally offered during the daytime hours. Residents were surveyed regarding their knowledge of and participation in the aerobics class.

\section{Perceived health status}

Perceived health status was measured by one question, "How would you describe your health?" with choices of "excellent", "good", "fair", and "poor".

\section{Participation in the aerobic exercise class}

To measure participation in the exercise class, two questions were asked: 1) Have you ever been to the aerobic exercise class organized by the resident center? 2) Have you participated in the aerobic exercise class organized by the resident center in the past month?

\section{Other physical activity}

Three previously validated items were adapted from the Behavioral Risk Factor Surveillance Survey (Centers for Disease Control and Prevention, 2001) to measure the frequency and duration of various types of physical activity. These questions were: 1) "On average, how many days per week do you engage in physical activity?", 2) "On those days that you are physically active, about how many minutes per day do you spend being physically active?", 3) "In general, what types of physical activities are you involved in on regular basis (check all that apply)?" 


\section{Results}

Prevalence of obesity and perceived health Figure 1 shows that most of the respondents (79\%) were overweight $(49.2 \%)$ or obese $(29.8 \%)$. Participants tended to rate their health as excellent, good or fair (see Figure 2).

Figure 1

Percentage of respondents in each BMI category

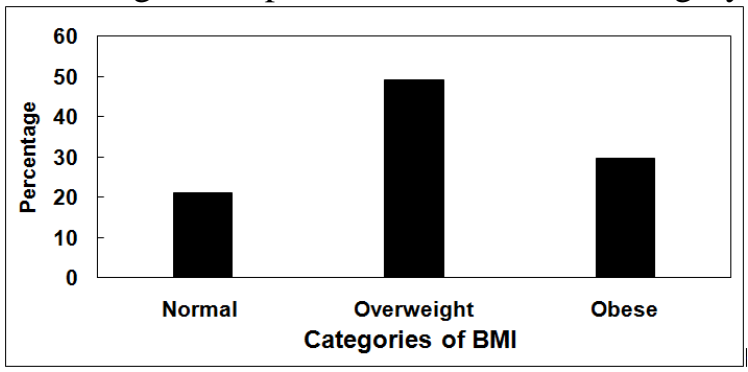

Figure 2

Respondents' self-reported health status

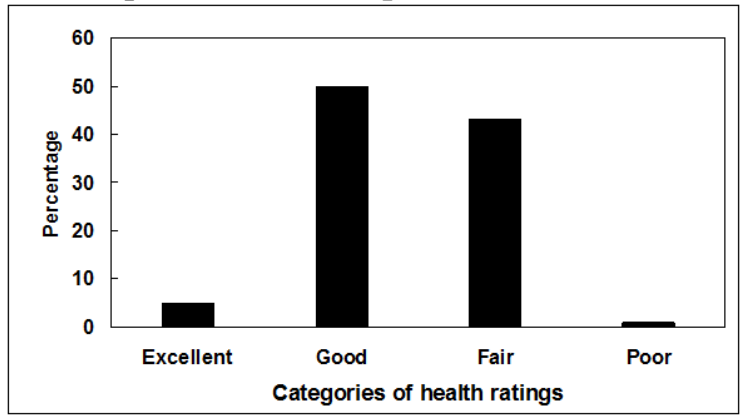

Participation in the aerobic exercise class

Most respondents $(78.1 \%)$ had heard about the aerobics class. However, only $24.6 \%$ percent of the respondents reported ever having attending a class session, and all of those were women. Of those who had ever attended a class session, only $30 \%$ had attended a session within the last month. Attendance was not related to weight status or to perceived health status.

\section{Other physical activity}

$41.9 \%$ of the participants reported being physically active 1 to 2 days a week, $33.1 \%$ were active 3 to 4 days a week, and only $22.3 \%$ of participants reported being physically active 5 to 7 days a week. Figure 3 shows the duration of the activity on those active days. Summarizing, we see that the majority of participants were generally inactive, with only $41.9 \%$ sustaining their activity as long as is recommended for healthy adults (Haskell et al., 2007).

\section{Figure 3}

Duration of physical activity on an active day

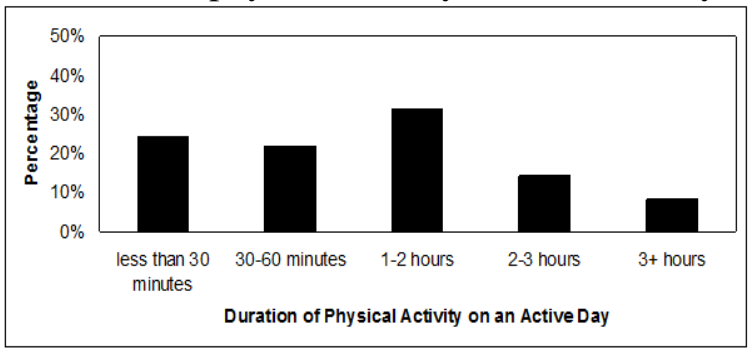

Types of activity reported are shown in Figure 4. Walking was the most common type of physical activity for both men and women. There are significant gender differences in other reported physical activities, in that housework was a more prevalent type of activity for women than men $(\mathrm{p}=.000)$ while yard work are more prevalent activity than women $(\mathrm{p}=.006)$. While more women reported going to exercise class than men $(\mathrm{p}=.015)$, men reported to be more engaged in sports than did women $(\mathrm{p}=.002)$.

\section{Figure 4}

Types of physical activities by gender

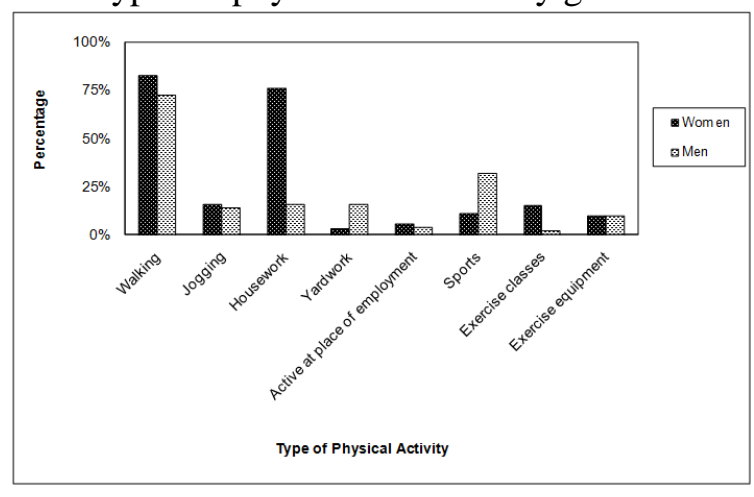

\section{Barriers to attend the aerobic class}

From a question that was asked for reasons of not attending the aerobic class and other 
activities, the most common reason was that they did not have time to attend the class due to their work. Needing child care was another reason. Approximately $74.3 \%$ said they were not interested in this program and preferred some other form of exercise, About $12 \%$ stated that the schedule was not convenient and about $8 \%$ (all men) said the classes were only for women.

\section{Discussion}

This is one of the few reported examinations of physical activity among recently immigrated, low-income Mexican American adults. It is noteworthy that low level of participation in physical activity was reported despite the existence of an on-site, no-cost aerobics program that obviates several of the usually reported barriers to exercise (Marquez \& McAuley, 2006). This report of low level of physical activity is consistent with the high level of overweight and obesity we found in this sample, and also consistent with the previous research (Crespo, Smit, Carter-Pokras, \& Andersen, 2001; Marquez \& McAuley, 2006).

There may be several reasons for the low participation in this on-site aerobic program. First, we cannot rule out the possibility that this particular program was unappealing, as most who tried it did not maintain participation. Second, the perception for physical activity might be different in this sample compared to the sample in other ethnic groups. The physical activities reported in this study were similar to those reported among other Latino samples (Evenson, Sarmiento, Macon, Tawney, \& Ammerman, 2002), in which women indicated that sports were for men, while housework was physical activity and was expected for women. Consistent with the findings of Crespo, Keteyian, Heath, \& Sempos (1996) for a general population, the most frequent physical activity reported by women in this study was walking, while about $78 \%$ of the women reported household chores as physical activity. The program was apparently perceived as appropriate for women only based on the results of this study. Our finding suggested that physical activity programs should take specific gender needs into consideration for this population. In addition, physical activity programs should be tailored to specific preferences based on the targeted population when possible. Prior to establishing any new activity programs, participants should be polled to determine what characteristics would be most appealing.

More than $75 \%$ of our respondents were found to be overweight or obese. However, the high rate of overweight and obesity was in stark contrast to the respondents' own perceptions of their health because the majority of respondents $(55.7 \%)$ reported that their health was "good" or "excellent." This response indicates that participants think that health status refers to the presence of a disease. Similarly, a study by Zsembik and Fennell (2005) found no significant association between self-rated health and obesity in Mexicans residing in the U.S. It is quite clear from our finding that the risk implied by obesity is not taken into account by our sample because they tended to rate their health as fair, good, or excellent in spite of the high BMIs. Educational programs designed for this population should emphasize the seriousness and immediacy of the risks to one's health associated with overweight/obesity.

Our results need to be interpreted with some caution because the sample was (a) small, (b) limited to one residence complex, and (c) not exhaustive. The latter issue is common in survey research; in the present instance, $41 \%$ of the households provided usable data. However, if there is a self-selection bias, it is likely to be in the direction of overestimating reported exercise levels, as those who did not engage in the socially approved behavior of exercise might be reluctant to participate in the study. To increase the rate of responding by males, it might prove useful to provide separate questionnaires for men and women; gender-specific instruments might elicit more responses from males. Furthermore, this study suggested that this population is hard to reach, thus establishing good connections with community leaders and staff is a crucial step to conduct research in this population. 


\section{Conclusion}

Previous studies suggested that Latinos present low levels of leisure-time physical activity and higher level of overweight and obesity which lead to risk for low levels of cardiovascular fitness and other diseases. The finding of this study provided valuable insights on the risk perception of being overweight and its connection to health, as well as the useful information about the barriers to the physical activity and preferences for specific physical activities for this population. Intervention program should take these variables into consideration.

This study was supported by CDC grant\# DP000209-01 to the Center for the Promotion of Healthy Lifestyles and Obesity Prevention. Its contents are solely the responsibility of the authors and do not necessarily represent the official views of the CDC.

References

Bernstein, M. S., Costanza, M. C., \& Morabia, A. (2004). Association of physical activity intensity levels with overweight and obesity in a population-based sample of adults. Preventive Medicine, 38, 94-104.

Brownson, R. C., Eyler, A. A., King, A. C., Brown, D. R., Shuy, Y. L., \& Sallis, J. F. (2000). Patterns and correlates of physical activity among US women 40 years and older. American Journal of Public Health, 90, 264-270.

California Department of Health Services (2005). The Economic Costs of Physical Inactivity, Obesity, and Overweight in California Adults: Health Care, Workers' Compensation, and Lost Productivity. Sacramento, CA: California Department of Health Services. www.dhs.ca.gov/ps/cdic/cpns/press/downloads/CostofObesityFullTechnicalReport.pdf

California Health Interview Survey (2003). University of California, Los Angeles: UCLA Center for Health Policy Research.

Carnethon, M. R., Gulati, M., \& Greenland, P. (2005). Prevalence and cardiovascular disease correlates of low cardiorespiratory fitness in adolescents and adults. Journal of the American Medical Association, 294, 2981-2988.

Centers for Disease Control and Prevention. (1998). Physical Activity and Health: A Report of the Surgeon General. Washington, DC: United States Superintendent of Documents.

Centers for Disease Control and Prevention. (2001). Behavioral Risk Factor Surveillance System Survey Questionnaire. Atlanta, GA: US Department of Health and Human Services, Centers for Disease Control and Prevention.

Crespo, C. J., Keteyian, S. J., Heath, G. W., \& Sempos, C. T. (1996). Leisure-time physical activity among US adults: Results from the Third National Health and Nutrition Examination Survey. Archives of Internal Medicine, 156, 93-98.

Crespo, C. J., Smit, E., Carter-Pokras, O., \& Andersen, R. (2001). Acculturation and Leisure-time physical inactivity in Mexican American Adults: Results from NHANES II, 1988-1994. American Journal of Public Health, 91, 1254-1257.

Erlichman, J., Kerbey, A. L., \& James, W. P. (2002). Physical activity and its impact on health outcomes. Paper 2: prevention of unhealthy weight gain and obesity by physical activity: an analysis of the evidence. Obesity Reviews, 3, 273-287.

Evenson, K. R., Sarmiento, O. L., Macon, M. L., Tawney, K. W., \& Ammerman, A. S. (2002). Environmental, policy, and cultural factors related to physical activity among Latina immigrants. Women and Health, 36, 43-56.

Eyler, A. A., Matson-Koffman, D. M., Young, D. R., Wilcox, S., Wilbur, J. E., Thompson, J. L., et al., (2003). Quantitative study of correlates of physical activity in women from diverse racial/ethnic groups: Women's Cardiovascular Health Network Project Introduction and Methodology. American Journal of Preventive Medicine, 25, 5-10. 
Weiss, J.W., Rubin, D., and Gomel, J.N. / Californian Journal of Health Promotion 2009, Volume 7, Special Issue (Obesity Prevention), $131-138$

Flegal, K. M., Carroll, M. D., Ogden, C. L., \& Johnson, C. L. (2006). Prevalence and trends in obesity among US adults, 1999-2000. Journal of the American Medical Association, 288, 1723-1727.

Fogelholm, M., \& Kukkonen-Harjula, K. (2000). Does physical activity prevent weight gain - a systematic review. Obesity Reviews, 1, 95-111.

Goel, M. S., McCarthy, E. P., Phillips, R. S., \& Wee, C. C. (2004). Obesity among US immigrant subgroups by duration of residence. Journal of the American Medical Association, 292, 28602867.

Gregg, E. W., Cheng, Y. J., Cadwell, B. L., Imperatore, G., Williams, D. E., Flegal, K. M., et al. (2005). Secular trends in cardiovascular disease risk factors according to body mass index in US adults. Journal of the American Medical Association, 293, 1868-1874.

Haskell, W. L., Lee, I.-M., Pate, R. R., Powell, S. N., Blair, B. A., Franklin, C. A., et al. (2007). Physical activity and public health: Updated recommendation for adults from the American College of Sports Medicine and the American Heart Association. Medicine and Science in Sports and Exercise, 39, 1423-1434.

Heini, A. F., \& Weinsier, R. L. (1997). Divergent trends in obesity and fat intake patterns: the American paradox. American Journal of Medicine, 102, 259-64.

Hubert, H. B., Snider, J., \& Winkleby, M. A. (2004). Health status, health behaviors, and acculturation factors associated with overweight and obesity in Latinos from a community and agricultural labor camp survey. Preventive Medicine, 40, 642-651.

Littman, A. J., Kristal, A. R., \& White, E. (2005). Effects of physical activity intensity, frequency, and activity type on 10-year weight change in middle-aged men and women. International Journal of Obesity, 29, 524-533.

Marquez, D. X., \& McAuley, E. (2006). Social cognitive correlates of leisure time physical activity among Latinos. Journal of Behavioral Medicine, 29, 281-289.

Mokdad, A. H., Marks, J. S., Stroup, D. F., \& Gerberding, J. L. (2004). Actual causes of death in the United States, 2000. Journal of the American Medical Association, 291, 1238-1245.

Nelson, T. F., Gortmaker, S. L., Subramanian, S. V., Cheung, L., \& Wechsler, H. (2007). Disparities in overweight and obesity among US college students. American Journal of Health Behavior, 31, 363-373.

Ogden, C. L., Carroll, M. D., Curtin, L. R., McDowell, M. A., Tabak, C. J., \& Flegal, K. M. (2006). Prevalence of overweight and obesity in the United States, 1999-2004. Journal of the American Medical Association, 295, 1549-1555.

Sanchez-Johnson, L. A. P., Fitzgibbon, M. L., Martinovich, Z., Stolley, M. R., Dyer, A. R., \& Van Horn, L. (2004). Ethnic differences in correlates of obesity between Latina-American and Black Women. Obesity Research, 12, 652-660.

Schmitz, K. H., Jacobs, D.R., Leon, A.S., Schreiner, P. J., \& Sternfeld, B. (2000) Physical activity and body weight: associations over ten years in the CARDIA study. International Journal of Obesity, 24, 1475-1487.

Weiss, J. W., \& Weiss, D. J. (2002). Recruiting Asian-American adolescents for behavioral surveys. Journal of Child and Family Studies, 11, 143-149.

Zsembik, B. A., \& Fennell, D. (2005). Ethnic variation in health and the determinants of health among Latinos. Social Science and Medicine, 61, 53-63.

Author Information

*Jie W. Weiss, Ph.D.,

California State University, Fullerton

Department of Health Science

800 N. State College Blvd.

Fullerton, CA 92834, USA 
Weiss, J.W., Rubin, D., and Gomel, J.N. / Californian Journal of Health Promotion 2009, Volume 7, Special Issue (Obesity Prevention), $131-138$

Phone: (714) 278-4388

Email: jweiss@fullerton.edu

Daniela Rubin, Ph.D.

California State University, Fullerton

Department of Kinesiology

Jessica N. Gomel, Ph.D.

California State University, Fullerton

Department of Child and Adolescent Studies

* corresponding author 